\title{
Digital Working Life: Some Introductory Reflections
}

The development of technology and its ensuing impact on society and working life has taken different expressions in the course of history. Historically, the execution and organisation of labour have always been characterised by the technology it has appropriated. During the 18th and 19th centuries, the steam engine contributed to the industrialisation of much of Europe and North America; during the 20th century, the combustion engine and the electric engine coincided with the development of centralised and large-scale production. These processes were based on the core technologies of their era, but they were also processes that were closely linked to an infrastructure that was undergoing change, urbanisation, globalisation and not least the emergence of wage labour and a capitalist commodity market. Social change should be seen as an interaction between technology and the conditions of production. This means that social change can in itself be technologically driven, but it does not mean that technology alone determines social change. Historical changes do not follow any predetermined course; rather, historical changes require human actions. In this special issue, "Digital Working Life", we examine the digitalization of working life. Although none of the authors explicitly discuss historical driving forces, the five articles do revolve around the relationship between the organisation of labour and technological change. All articles also highlight knowledge gaps that the authors believe are important to overcome if we are to avoid a development that could lead toward a dystopian future.

For several decades now, we have found ourselves in the middle of an accelerating digitalization of both society and working life. While this process in many ways is tangible, it is also a process that is difficult to pinpoint and define. Clearly, the conditions and organisation of working life are undergoing changes, but which direction this development is moving toward is not obvious. This problem is perhaps, as Giovanni Dosi (1982) and Ulrich Beck (1995) point out, due to the difficulties inherent in formulating a new techno-economic paradigm that is based on contemporary norms and concepts (in this case, the norms and concepts of industrial society). What is clear, however, is that the rapid development of the semiconductor technol-

* Assoc. Prof. Dr. Mikael Ottosson, Department of Urban Studies, Malmö University, Sweden, Email: mikael.fredrik.ottosson@mah.se.

Prof. Dr. Wenzel Matiaske, Helmut-Schmidt-University/University of the FAF Hamburg, IPA Institute for Employment Relations and Labour, Holstenhofweg 85, 22043 Hamburg, Germany and Research Fellow at German Institute for Economic Research/SOEP Berlin, Email: matiaske@hsu-hh.de

Asst. Prof. Dr. Simon Fietze, University of Southern Denmark, Department of Entrepreneuership and Relationship Management, Alsion 2, 6400 Sønderborg, Denmark,

Email:simonf@sam.sdu.dk. 
ogy and the microchip (Moore's Law) contributes to drastically changing the world. According to Brynolfsson and McAffe (2014), the development of digital technology and its ever-increasing applications and declining costs are to be viewed as an indicator of a new, emerging techno-economic paradigm.

Although digital technology has led to the birth of a number of new products and applications, the impact of it is perhaps most clearly seen in the adaption of machines and equipment that were developed in an analogical context, such as trucks, lorries and industrial machinery. Originally analogue equipment has been adapted to enable digital control and management (the Internet of Things). Johansson, Abrahamsson, Kåreborn, Fältholm, Grane, and Wykowska's article addresses what will happen in the next stage of this development as these digitalized machines become connected within a new infrastructure, i.e., an industrial Internet. Although the authors do not explicitly use this terminology, their arguments also highlight the standpoint that "Industry 4.0 " is not just a new way of conceptualising production but also a new industrial paradigm.

The digitalization process that society is currently undergoing has led to a dramatic change in the organisation of human labour and how workplaces are being reshaped. We need only glance $25-30$ years back to see that the world today is a very different place. The cell offices of yesterday have been replaced by open, activitybased office landscapes; the typewriters, calculating machines and stationary telephones (equipped with spinning dials) that were used by office staff have been replaced by portable computers and mobile phones. Manual work, such as it once was executed in the manufacturing and healthcare industries, has also changed. Whether or not by design, digital technology has contributed to the dissolution of traditional temporal and spatial conditions of work.

The framework that previously circumscribed and regulated the contents of work, as well as when, where and how work was carried out, is being re-negotiated and is influencing the average worker's daily life. However, these changes are expressed in different ways, and research in the field indicates that these changes are progressing in several, different directions. Some workers experience that their working conditions are becoming more and more borderless with increased self-determination as a result, while others experience a very different development in which their labour is becoming fragmentized, divided into subsections and subjected to ever stricter control. Digital technology via computers, phones, or integrated into machines and equipment, create conditions that allow labour to be standardised in a way that was not possible in a previous analogical context. In some labour market segments, this has led to work becoming degraded and emptied of content. Several researchers have pointed out that the labour markets are being divided and undergoing a segmentation process (e.g. Levy \& Murnane, 2012). However, as Eichhorst, Hinte, Rinne, and Tobsch point out in their article, in fact, this development predates the digital era. Although it may be difficult to observe any direct causality, research on 
working life does show that workers in some segments of the labour market are increasingly expected to take their own initiatives and are afforded higher levels of trust, while workers in other segments face growing distrust, control and surveillance.

In one way or another, the authors of the articles in this special issue all examine the conceptual dichotomy of "autonomy and control". They adopt a bottom-up perspective and discuss the average worker's options to independently make their own decisions and manage their own work execution. In the Taylorist or Fordist production systems, which were borne from a scientifically based attempt to establish a maximum division of labour and pin down the basic movements of work (Braverman, 1999), control was of the essence. However, with regards to control and surveillance, digital technology has brought with it new possibilities that run the risk of reinforcing a traditional culture of control. In line with Braverman (1999) and the labour process tradition some researchers, for example, Brown, Lauder, and Ashton (2010), use the term "digital Taylorism" when analysing the new labour market. This aspect of digitalization is evident in Tranvik and Braten's article that references empirical research on the application of "field technologies" in various industries. According to their results, digital control and surveillance appear to be very much alive in the working life of today. Their article shows that the gathering of information is used by management, customers and authorities in order to limit the autonomy of the working individual.

However, as Bader and Kaiser point out in their article, this development can be seen as a number of paradoxes. They argue that a development in the opposite direction are occurring simultaneously in the sense that the complexity of work is increasing and that technology in some contexts contributes to increased autonomy for some workers. While technology allows for new methods of control, many organisations are being flattened out, and workers are required to take their own initiatives and take responsibility for their own participation and commitment. Here too, digital technology is having an impact on the development - not least with regard to the potential of the digital technology to cause spatial dissolution (Duffy, 2008). In other words, digital technology seems to have both emancipating and monitoring potentiality at the same time.

Structurally and conceptually, industrial society was based on a desire for control within fixed spatial borders. A calculable and controllable spatial and temporal disciplinary framework was needed in order to plan production and maintain discipline within the workforce. Preindustrial society's focus on the execution of the task at hand became replaced by a focus on measurable and calculable (clockable) work time (Negrey, 2012). The basic foundation of industrial society required temporal discipline, and the desire to control how workers spend their time must be viewed within the context of the very essence of salaried labour: An individual who works for a salary does not sell the results of their work, but rather their capacity to work 
according to a set, pre-agreed time frame (Braverman, 1999). In the industrial society, production, therefore, became centralised and confined to factories. In many production situations, detailed work rules were established, with clear temporal frameworks that designated when, for how long, in which order, how often and by whom a work task was to be performed (Thompson, 1991). Distrust was in many ways the fundamental principle of organised labour in industrial society. The spatial and temporal dissolution brought about by digital technology does not necessarily conflict entirely with the control structures of the classical industrial organisation. Rather, according to both Tranvik and Braten and Kaiser and Bader, it's obvious that this structure of control can be found in various aspects of digital working life as well.

According to the articles in this special issue, information and communication technologies (ICT), Internet of Things (IoT), Artificial Intelligence (AI) and other digital infrastructures have not only contributed to changing how work is organised and carried out, but also to how we perceive and conceptualise labour. One possible scenario might be that salaried labour, which has dominated institutional society, will turn out to be merely a historical parenthesis, and that we are now seeing a platform economy (e.g. collaborative economy platforms such as Airbnb and crowd-working platforms such as WorkHub) emerging in its place. This would implicate structural social changes with consequences that reach far beyond the workplace. Eichhorst, Hinte, Rinne, and Tobsch, in their article, study the role of the platform economy in Germany. They state that the platform economy has not yet increased dramatically, but according to their study it can be concluded that various platform services have become an increasingly important source of extra income for many people. In a somewhat broader perspective, the relationship between work and income is not as straightforward as it used to be. Atypical, flexible forms of employment such as fixed-term and project employment have replaced traditional stable forms of employment. Eichhorst, Hinte, Rinne, and Tobsch argue that welfare and social insurance systems need to be reformed in order to comply with a future platform economy as well as a labour market that is becoming increasingly flexible. A "social security system 4.0" is needed in response to "Industry 4.0".

Digital communication technology has entailed that the boundaries of work are becoming increasingly vague. Equipped with smartphones and laptops, and more or less permanently connected, employees often switch between private activities and work tasks independent of the time of day. Private tasks are carried out during working hours, but as demonstrated by Bellman, Grunau, Müller, and Wolter, it's common for employees to perform work tasks outside their working hours. This is, as Bader and Kaiser state in their article, a development that has both positive and negative implications. A positive aspect is that digital technology seems to offer better opportunities to manage the complexities of combining work and private life. But a corresponding negative aspect is that the free time needed for recovery may be too limited. Free time becoming less free. 
Several studies indicate that the norm dictating loyalty through availability is historically strong and that a substantial number of employees feel that they are expected to work in their free time (e.g. Derks, van Mierlo \& Schmitz, 2014; Ottosson \& Rosengren, 2015). According to the study presented in the article of Bellman, Grunau, Müller, and Wolter, this expectation is linked to possibilities that have emerged in the wake of digital technology. In their study, it appears that ICT-users, especially officials and managers, work more hours than non-ICT users. Obviously, there seems to be a connection between the availability of mobile communications equipment and performed working hours.

This special issue originated from discussions during a seminar held on April 13-15, 2016, at the International University Center Dubrovnik (IUC), Croatia. A large number of papers have been submitted both before and after the seminar and its call for papers. We end this introduction by expressing our sincere appreciation to all seminar participants for contributing interesting papers and comments. We like to thank the DAAD for their fellowships supporting the seminar.

\section{References}

Beck, U. (1995). Reflexive modernization: Politics, tradition, and aesthetics in the modern social order. Stanford, CA: Stanford University Press.

Braverman, H. (1999). Labor and monopoly capital: The degradation of work in the twentieth century (25th Anniversary Ed.) New York, NY: Monthly Review.

Brown, P., Lauder, H., \& Ashton, D. (2010). The global auction: The broken promises of education, jobs and incomes. Oxford: Oxford University Press.

Brynjolfsson, E., \& McAfee, A. (2014). The second machine age: Work, progress, and prosperity in a time of brilliant technologies. New York, NY: W. W. Norton \& Company.

Derks, D., van Mierlo, H., \& Schmitz, E. B. (2014). A diary study on work-related smartphone use, psychological detachment and exhaustion: Examining the role of the perceived segmentation norm. Journal of Occupational Health Psychology, 19(1), $74-84$.

Dosi, G. (1982). Technological paradigms and technological trajectories. Research Policy, 11, 147-162.

Duffy, F. (2008). Work and the city. London: Black Dog Publishers.

Levy, F., \& Murnane, R.J. (2005). The new division of labor: How computers are creating the next job market. Princeton, NJ: Princeton University Press.

Negrey, C. (2012). Work time: Conflict, control, and change. Cambridge: Polity. 
Ottosson, M., \& Rosengren, C. (2015). The Swedish Confederation for Professional Employees (TCO) and trust-based working hours 1950-1970. Management Revue, 26(1), 52-68.

Thompson, E. P. (1991). Customs in common. London: Merlin.

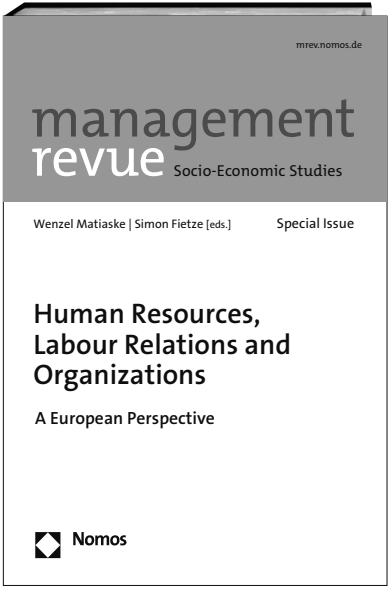

\section{Human Resources, Labour Relations and Organizations}

A European Perspective

management revue. Socio-Economic Studies (mrev) - Special Issue

Edited by Prof. Dr. Wenzel Matiaske and

Ass. Prof. Dr. Simon Fietze

2017, 238 pp., pb., € 54.00

(Special price for subscribers: € 40,50)

ISBN 978-3-8487-4055-0

eISBN 978-3-8452-8354-8

nomos-shop.de/29502

For a quarter of a century, the management revue has been a medium of research in administration science and management studies. First and foremost, the journal publishes works by authors who investigate the institutional particularities of management and organisations in a European context. The emergence of this prioritisation does not come as a surprise, as the socio-economic perspective of the management revue suggests that this research topic is embedded in specific temporal and spatial social contexts. The assortment of contributions made to this edition, which provides insights into the spectrum of research published in the management revue, aims to illustrate this prioritisation in the fields of human resource management, labour relations and theory formation.

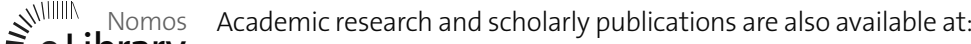 હ eLibrary www.nomos-elibrary.de}

To order please visit www.nomos-shop.de, send a fax to (+49)7221/2104-43 or contact your local bookstore. All costs and risks of return are payable by the addressee.

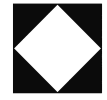

